\title{
THE ANTE-NATAL TREATMENT OF VENEREAL DISEASE-GONORRHOEA
}

\section{Discussion}

DR. F. J. BARKER said he had been particularly interested to hear from Mr. Eardley Holland of the extraordinary paucity of cases of gonorrhœa, and particularly of cases of ophthalmia neonatorum, in large clinics, and especially in those under Mr. Holland's care. It was a very great change compared with the conditions the speaker remembered, all too well, when, thirty years ago, he was junior house-surgeon in one of the largest ophthalmic hospitals in Great Britain, where practically every morning, except Sunday, for eighteen months, was passed in washing out gonorrhœal eyes. Most of those eyes were in a pitiable condition, perhaps chiefly because the cases were seen so late. In many, the end result was appalling. It was no exaggeration to say that 20 per cent. of the blindness in the world was at that time due to this disease. Hence there was ground for congratulation on the present state of affairs in comparison with the past, and great hope for the future.

As to the treatment of gonorrhœa in women, he felt bound to admit that the results did not seem to him encouraging. The main hope at the moment lay along the path of prevention. Recently he met a well-known urologist and asked him about gonorrhœa in men, and that gentleman said he never again wished to see a case of gonorrhœa, as he felt such cases nearly always brought discredit. As to treatment of gonorrhœa in women, he quite recently met a venereal disease specialist who agreed that the position regarding the established disease in women was far from satisfactory, but he added that a vaccine was being worked at which was likely to change the situation very much for the better. He (Dr. Barker) would believe that when he saw it. At present he agreed with Dr. Lacey that, with the exception of gonorrhœal rheumatism, treatment by vaccines had been melancholy 


\section{BRITISH JOURNAL OF VENEREAL DISEASES}

in its results. For that reason he was chiefly hopeful of the results of efforts being made to educate the public. Were doctors responding to the need by founding educational centres where lectures on the dangers and the need for early treatment could be given? Parents so instructed could hand on the teaching to their children.

With regard to inflammation in the tubes due to gonorrhœa, he wished to advance a plea for a more conservative and expectant attitude on disease in the tubes. Within the last year or two there had arisen, to his knowledge, a school of distinguished gynæcologists, surrounded by a younger coterie of enthusiastic admirers, who advocated the treatment of the inflamed tube on the same basis as that of an inflamed appendix. This the speaker regarded as a mere counsel of despair, as it meant the giving up all idea of being able to distinguish between the various degrees of virulence by which this disease was characterised, there being all shades of intensity. This idea of whipping out every tube as soon as it was known to be inflamed should, he thought, be severely condemned. He would value the opinions of the openers on this point. His own view was that a respectable percentage of gonorrhœa-infected tubes were capable of complete functional restoration given care in treatment and patience. Admittedly there were many cases in which the abdomen had to be opened, but even in regard to those there was room for a good deal of conservatism. He thought many could be cured by laying open the tubes instead of removing them altogether.

In conclusion, he exhibited a chart of a case, with the object of showing there was no case so severe that one need abandon the motto "Nil desperandum." In that case the man who had infected the woman came and told the speaker he believed he had done so. Swabs showed that he had, and at the woman's next period the disease ascended into the right tube. He got her into a hospital where he was able to keep in close touch with her. That was in IgII. It was decided (wrongly, he now thought) to remove the right tube, and this was carried out. A few days later the right ovary was infected. The abdomen was again opened, an incision made in the ovary, pus was evacuated, and the tube left in position. In order to deal with this ovary satisfactorily it had to be separated from the bladder, to which it was found to be 


\section{ANTENATAL TREATMENT OF GONORRHEA}

adherent. In the course of that a little tear occurred, resulting in a urinary fistula. A fortnight later the left tube and ovary became infected, and they were removed. At the time the fistula became established temperatureswhich formerly had reached $105^{\circ} \mathrm{F}$.-mounted to $107^{\circ}$, $108^{\circ}, \operatorname{I09}^{\circ}, \operatorname{I09}^{\circ} 4^{\circ}$, and it seemed impossible for the patient to recover. But after many months she did recover. $\mathrm{He}$ heard nothing more of her for five years; then one day she recognised him and said she was married and had two nice children. The first of these was delivered by Cæsarean section, and he was much amused by a note in the report to the effect that the surgeon had removed the right Fallopian tube! What it was he actually did remove the speaker did not know; it was certainly not the Fallopian tube.

Dr. DENNIS VINRACE asked in what circumstances a woman was considered to be sterilised. He understood that in the case related by Dr. Barker both tubes and one ovary had been removed, and the other ovary drained, and yet the lady gave birth to two beautiful children.

Col. BURKE said he was very interested in what $\mathrm{Mr}$. Eardley Holland said about the paucity of cases of gonorrhœa in pregnant women in his experience. $\mathrm{He}$ himself had an entirely different experience. Mr. Holland's figures suggested to him two things: first, that the bulk of female gonorrhœa was seen in the nonpregnant woman, and secondly, that a tremendous amount of sterility must be due to the disease. With regard to diagnosis, he did not think any one nowadays was inclined to diagnose gonorrhœa in the female on clinical signs alone ; there were so many inflammatory conditions and discharges that it was essential, not only in suspicious cases, but in all, that slides and cultures should be resorted to. He also thought the provocative process should be applied in a suspicious case. Recently he had had experience of provocation with a milk protein. In taking smears before a provocative injection one found many atypical things which stained irregularly, not definitely gram-negative, and after a provocative injection of aolan smears from the cervix were found to be swarming with typical gonococci. He believed that if gonorrhœa was more often looked for in gynæcological practice it would oftener be found. But he did not think any information could be based on a negative smear. 
Mr. Hamish Nicol said he had no facilities for making cultures, and he diagnosed gonorrhœa by taking smears. He never had any hesitation about lightly packing the cervix up to six months and sometimes longer, and the only indication he had for not packing the cervix was if the patient showed signs of aborting. Aquaflavin, 2 per cent. in glycerine, gave results as good as any; otherwise he treated pregnant gonorrhœa cases in the same way as any other cases of the disease.

Dr. Sharp said it was not often it fell to his lot to see a pregnant woman suffering from this disease; he was mostly concerned with children. In children his experience with aquaflavine and glycerine was that it was inferior to protargol and glycerine. In two series of cases he had used one treatment to one series, and the other treatment to the other, and protargol gave the more rapid result.

Dr. Violet RusSell said she had been much struck by the brilliance of Dr. Lacey's figures; his results were a tribute to the soundness of his methods.

With regard to Mr. Eardley Holland's questions, there were many pregnant cases of gonorrhœa at Guy's Hospital, and in seven years she had not seen one of abortion which could be attributed to the treatment; in fact, there had been very few cases of abortion in association with gonorrhœa. One woman who aborted had gonorrhœa before she became pregnant, the tube being invaded before that event. She had had some metritis, with irregular losses, and menorrhagia.

It was not the custom at Guy's to pack the cervix, but it was painted with strong antiseptics in some cases, without bad results; also tampons had been used without any detrimental effect. She did not consider that gonorrhœa was a more serious and severe disease in the pregnant than in the non-pregnant woman. Some cases of the disease during pregnancy were very acute, others mild, and some non-pregnant cases were very acute. Some mild cases occurred during pregnancy, which had cleared up rapidly.

She had very much enjoyed both the opening papers.

Dr. DoRothy Logan desired to thank both the openers for their interesting papers. It had been very surprising to her to hear Mr. Eardley Holland's figures ; in her own small clinic in connection with King's College Hospital 


\section{ANTENATAL TREATMENT OF GONORRHCA}

she had quite a number of cases which had been referred there from the ante-natal maternity department. At Clapton there were twelve hospital beds for the venereal disease cases in a hospital with over sixty maternity beds, and for those twelve beds she had about ${ }_{50}$ cases a year.

She was able to corroborate what Dr. Violet Russell said about treating the cervix ; she did not find trouble due to treating cases during pregnancy. The ordinary urethral probe, dressed with a small swab of wool, held with a light pen-holder touch, carried no risk of penetrating the internal os, even in the case of a pregnant cervix.

With regard to the conservative treatment of diseased tubes, she heartily endorsed Dr. Barker's recommendation. An interesting case came to her first in I9I9, at a postnatal clinic, complaining of a discharge, which was worse because she had been nursing her husband after rheumatism. She had had a slightly premature confinement, and after the confinement an operation for "appendicitis." Probably the appendix was removed. Obviously there was a gonococcal discharge. She was treated. At one time she had infection of one tube, at another time of the other, and there were exacerbations, when she was quite ill. An attempt to receive her into hospital failed. When a bed was available she was better. She had patient care and treatment, and now possesses two beautiful children; she was still under the speaker's observation. She had been under the speaker's charge for both confinements, and they had been straightforward. She had one miscarriage between them, and at one time she had been carefully watched, and the speaker had been a bit anxious about her for a couple of weeks, for she could not be sure the patient was not going to have an ectopic gestation. It turned out not to be so, however.

Dr. WRIGHT (Norwich) said he agreed with what had been said about the conservative treatment of the tubes. $\mathrm{He}$ had had many cases in which a vaginal examination revealed a large tender lump. Such a case was that of a woman, aged twenty-seven, who had been infected with gonorrhœa by her husband. She had had one child, and was anxious for others. She had a violent flare-up, and a surgeon was sent for, who said he must open the abdomen, and might have to remove the tubes. This the 
patient refused. The condition quieted down, and the woman came back to the speaker. He had then just procured a diathermy apparatus, but was afraid to use it for this case; he told the patient he would not use it unless she got an opinion from a gynæcologist favourable to it. She came to London and consulted a gynæcologist, who said she was right to refuse operation, and he thought diathermy was worth trying. It was done, and the case cleared up, being negative to all tests. Fourteen months later when he saw her, she had had a baby, and the doctor in the case said there had been no trouble either before or at the confinement. Surgeons should study these conditions more; then they would not be so ready to open the abdomen and remove the tubes.

Dr. MARGaret Rorke said she also had much appreciated the papers. Concerning the small number of cases of gonorrhœa in pregnant women mentioned by $\mathrm{Mr}$. Eardley Holland, she did not think the cervix could have been very carefully inspected. In the Royal Free Hospital many of the cases having a considerable discharge were not gonorrhœal subjects; the discharge was only an exacerbation of the normal.

She did not think those having much experience in this kind of work considered that warts were evidence of gonorrhœea; their presence merely meant there was an irritating discharge.

With regard to "full-blown" evidence of gonorrhœe in pregnancy, some cases were persistently gonococcuspositive, though the woman had but little discharge; sometimes a gonorrhœa which had been present before pregnancy flared up when that event happened. With regard to the state of the tubes after delivery, in more than 2 per cent. of cases the tubes were found to be infected after delivery. In her clinic there had been only three bad pyosalpinx cases after delivery, one of them transitory.

She was sure gonorrhœa did not cause abortion per se. In her department a number of pregnant women came up at seven months, primiparæ, with gonorrhœa and a secondary infection superimposed. They needed fairly vigorous treatment.

With regard to Dr. Lacey's paper, she felt with him the difficulty in getting married cases to come for treatment. The unmarried woman could be arranged fer, but 


\section{ANTENATAL TREATMENT OF GONORRHEA}

the married woman was not, through a variety of circumstances, well treated; she had too many home ties, and had but little money for 'bus fares, etc.

With regard to urotropine for intravenous use in cases of pyelitis, she asked what was the strength employed. In her clinic there was a very bad $B$. coli pyelitis complicating pregnancy. She used only the old-fashioned massive doses of alkalies for two hours, with acriflavin by the mouth.

Sometimes warts could be made to disappear by keeping the patient dry and giving doses of vaccine at discrete intervals. Failing that, the patient was given gas and the warts clipped off, dressing afterwards with 5 per cent. phenol in glycerin for the first twenty-four hours. Healing took place in about four days.

Her experience in regard to infected tubes had been the reverse of Dr. Barker's. There were known to be one or two surgeons who were willing to open anybody, but, broadly speaking, she had found that gynæcological surgeons were very conservative and helpful in regard to salpingitis. In the majority of cases in her experience waiting had been proved to be the right policy.

Professor F. J. BRownE said, with regard to the paucity of gonorrhœa cases in Mr. Eardley Holland's series, the figures given were very extraordinary. At University College Hospital, where there were about 2,000 antenatal cases a year, there had been three proved gonococcal cases in the last three months. A statement was made that a case should not be treated as one of gonorrhœa unless the gonococcus was found. If that were to be the standard he was sure many cases would be missed ; in many cases the diagnosis had to be made on the clinical features alone. It must be remembered that the gonococcus was not lying simply in the vagina, it was deep in the peri-urethral glands and cervical glands, and it was most difficult to find. The gonococcus easily died, and was replaced by secondary organisms, and so in a long-standing case it might be quite impossible to find the gonococcus when the clinical features left little doubt about the disease. He thought cases with an excessive discharge should be treated as gonorrhœa, though without necessarily labelling them as such. These cases might infect the male, which was the only really conclusive proof.

v.D. 


\section{BRITISH JOURNAL OF VENEREAL DISEASES}

He agreed with Mr. Holland that gonorrhœa did not cause abortion, though he did not know why it should not do so, as the path was open from the cervix, so that an inflammatory condition of the decidua was easily understood. He had seen two or three cases in which he was almost sure treatment of gonorrhœa in pregnancy brought on premature labour. $\mathrm{He}$ would hesitate to swab the cervical canal with aquaflavin. He felt interested in Dr. Lacey's treatment with Glauramine. At one time the speaker tried salt solution in the treatment of gonorrhœa in pregnancy, and he got as good results from that as from protargol. The trouble was that by using local applications one did not get at the gonococcus; when the antiseptic preparations reached it, it was easily killed.

He was most interested in Dr. Lacey's statement as to the treatment of pyelitis in pregnancy by the injection of urotropine. He had had anxious times with pyelitis, and he would be delighted if he could cure the cases by injecting urotropine. Some said it only acted in an acid medium. Gall-bladder conditions, however, were treated by urotropine. He asked what was the dosage of urotropine used, and how frequently it was given.

He did not advise self-douching, as, in his opinion, it was dangerous and might cause urethritis when that had not previously existed.

With regard to the use of vaccines, he had found a detoxicated vaccine most useful, giving 5,000 millions to start with, and working up to I00,000 millions.

The ChaIrman (Col. Harrison) desired to express his own appreciation of the value of this discussion; he was sorry the audience was not larger. In the less frequent operations on infected tubes and the smaller number of cases of ophthalmia neonatorum he hoped one might see evidence of the success now being attained in the mass treatment of venereal disease. A gynæcologist had told him that, in comparison with previous years, one now saw but little severe disease in the tubes, and that he thought this was largely due to the better treatment of gonorrhœa, especially in women, at the present day. $\mathrm{He}$ had been told by a member of the staff of a large ophthalmic hospital that ophthalmia neonatorum was becoming rare. And there was some support for that in the latest Report of the Advisory Board for the Blind to the 


\section{ANTENATAL TREATMENT OF GONORRHEA}

Ministry of Health. The number registered as having contracted blindness under the age of twenty-one was I77 less, though the number on the register had increased. This the committee considered to be due to the measures which were undertaken for the prevention of blindness in infancy and childhood. It would be interesting to learn the experience of the gynæcologists present as to the incidence of tube disease now, and whether these gentlemen would give those engaged in treating venereal disease credit for the reduction in ophthalmia neonatorum.

Scepticism had been expressed on the subject of " onechild sterility," and it would be interesting to know what was the average family of the gonorrhœal mother. One author had stated that he thought the number in such a family averaged about the same as in the case of the nongonorrhœal woman.

He endorsed Dr. Lacey's plea for a liaison between the ante-natal and venereal disease departments; by real co-operation it might yet be possible to put the foot effectively on this and kindred diseases.

Mr. EARdLey Holland, in reply, said he had never enjoyed a discussion so much as he had enjoyed this one. So many points had been raised in it that it was impossible to reply to them all. In answer to the Chairman, one did not see so many cases of pyosalpinx now as formerly, and the same could be said of ophthalmia neonatorum. He did not doubt this was due to the improved methods of treating gonorrhœa, and to the splendid efforts of workers in the various venereal disease clinics. When he began practice, women were not treated for gonorrhœa ; they were told merely to use a vaginal douche, and even that was used perfunctorily.

Several speakers had expressed astonishment that such a very small number of cases of gonorrhœa had been seen in the ante-natal clinics and maternity wards under his charge. The remark that cases were probably overlooked was justified. In future, as a result of this meeting, he intended to tighten up the method of investigation in his clinics. For that reason alone he was glad to have heard the discussion.

He endorsed all Dr. Barker said as to the need for conservative treatment for infected Fallopian tubes. These cases could be divided into streptococcal and gonorrhœal. The first of these often required operation, 


\section{BRITISH JOURNAL OF VENEREAL DISEASES}

though one naturally preferred to wait for acute symptoms to subside. If operation was not done, there was a risk of general peritonitis, and operation might disclose an ovarian or other abscess. With gonorrhœal tubes the case was different. At the London Hospital the policy pursued in regard to these was very conservative. The late Dr. Herman and his successor, Dr. Andrews, were great upholders of the conservative tradition. But for several reasons operation might have to be done; for example, the patient might have several attacks every year of pain, peritonitis, fever. The tubes, however, were given a chance, and operation was seldom done unnecessarily. The difficulty about conservative treatment was the lack of accommodation ; the bed provision was very limited, and patients could not be retained under treatment for months, which was necessary for proper conservative treatment, with regular douching, etc. In answer to Professor Browne, he did say he would not diagnose gonorrhœa in the absence of bacteriological evidence merely because a patient had a suspicious discharge. A careful technique was required, and the culture tubes must never be allowed to cool either before or after inoculation. To have an incubator on the spot was therefore essential. 